\title{
Analisa Strategi Pemasaran Lillah Hijab Dengan Metode BCG (Boston Consulting Group) dan Swot
}

\author{
Ekie Gilang Permata ${ }^{1}$, Muhammad Rizki $^{2 *}$, Petir Papilo ${ }^{3}$, Silvia $^{4}$, Azzahra Mahabbah Zain $^{5}$ \\ Jurusan Teknik Industri, Fakultas Sains dan Teknologi, UIN Sultan Syarif Kasim Riau \\ J1. HR. Soebrantas No. 155 Simpang Baru, Panam, Pekanbaru, 28293 \\ Email: ekiegp@yahoo.com, muhammad.rizki@uin-suska.ac.id,pilo_ukm@yahoo.com, silvia@uin-suska.ac.id, \\ azzahramahabbahzain@gmail.com
}

\begin{abstract}
ABSTRAK
Lillah Hijab adalah sebuah industri rumahan yang memproduksi berbagai produk fashion seperti produk hijab. Penelitian ini dilakukan untuk menganalisis strategi pemasaran Lillah Hijab dengan menggunakan metode BCG Matrix dan Analisis SWOT. Hasil dari penelitian ini menggunakan matriks BCG dengan menghitung tingkat pertumbuhan pasar bahwa Lillah Hijab terletak pada posisi Question Mark sebesar 14,2 \% dan pada perhitungan pangsa pasar relatif bahwa posisi Lillah hijab menghadapi pangsa pasar yang rendah dan terjadi kondisi pertumbuhan yang tinggi dengan nilai sebesar 0,85. Hasil dari analisis SWOT terdapat beberapa bagian yaitu Faktor Internal, Faktor Eksternal, Matrik IE, dan strategi pemasaran yang efektif dalam meningkatkan penjualan Lillah Hijab. Strategi Perusahaan yang Efektif dalam Meningkatkan Penjualan Lillah Hijab adalah dengan Strategi S-O (Strengths-Opportunitties) melakukan kerjasama yang baik kepada karyawan dan distributor, melakukan potongan harga disetiap hari spesial, mempertahankan dan meningkatkan kualitas pada produk. Strategi S-T (StrengthsOpportunitties) menetapkan harga sesuai dengan perubahan harga bahan baku, tetap memperhatikan kebutuhan pelanggan tanpa merugikan perusahaan, dan menambah beberapa jenis produk yang baru dengan memperhatikan kualitas agar dapat bersaing dengan produk yang tidak sejenis maupun yang sejenis. Strategi W-O (WeaknessesOpportunities) menambah modal dengan melakukan kerjasama investor atau melakukan peminjaman kepada bank, melakukan kerjasama dengan agen-agen gunanya untuk memperluas area pemasaran, membuka toko sendiri di perkotaan, serta memperluas pangsa pasar dengan mengikuti strategi penjualan online, yang dan melakukan pengembangan produk agar menarik pelanggan. Strategi W-T (Weaknesses-Threaths) mengumpulkan informasi dalam pengembangan dan pemasaran produk dan melakukan kerjasama yang baik dengan penyedia bahan baku dan investor agar dapat meningkatkan kapasitas produksi.
\end{abstract}

Kata Kunci: Analisis SWOT, Pemasaran, Matrik BCG, Matrik IE

\begin{abstract}
Lillah Hijab is a home industry that produces various fashion products such as hijab products. This research was conducted to analyze the marketing strategy of Lillah Hijab using the BCG Matrix method and SWOT analysis. The results of data processing using the BCG matrix by calculating the market growth rate that Lillah Hijab is located in the Question Mark position of $14.2 \%$ and on the calculation of the relative market share that the position of Lillah hijab is facing a low market share and high growth conditions occur with a value of 0,85. The results of the SWOT analysis consist of several parts, namely Internal Factors, External Factors, IE Matrix, and effective marketing strategies in increasing sales of Lillah Hijab. Effective Company Strategies in Increasing Sales of Lillah Hijab is the S-O Strategy (Strengths-Opportunitties) to collaborate well with employees and distributors, make discounts on special every day, maintain and improve product quality. The $S$-T (Strengths-Opportunitties) strategy sets prices according to changes in raw material prices, still pays attention to customer needs without harming the company, and adds several types of new products with attention to quality so that they can compete with products that are neither similar nor similar. The WO (Weaknesses-Opportunities) strategy increases capital by cooperating with investors or making loans to banks, collaborating with agents to expand the marketing area, opening their own stores in cities, and expanding market share by following online sales strategies, which and do product development in order to attract customers. The W-T (Weaknesses-Threaths) strategy collects information in product development and marketing and establishes good cooperation with raw material providers and investors in order to increase production capacity.
\end{abstract}

Keywords: SWOT Analysis, Marketing, BCG Matrix, IE Matrix 


\section{Pendahuluan}

Era globalisasi sekarang ini sudah banyak pelaku usaha kecil atau industri rumahan memproduksi berbagai produk fashion seperti produk hijab atau kerudung. Semakin berkembangnya gaya hidup yang dinamis, modern dan modis yang mengakibatkan lahirnya keinginan untuk tampil lebih menarik, utamanya bagi kaum wanita dan tak terkecuali pada wanita muslimah. Hijab saat ini merupakan kebutuhan untuk para wanita muslimah. Para pelaku usaha kecil pada umumnya masih banyak yang berpendapat keliru bahwa apabila penjualan produknya masih terus meningkat maka usaha tersebut dianggap tidak mempunyai permasalahan yang sifatnya strategis, padahal pada kenyataannya yang terjadi adalah para pesaing sudah sedemikian kuat dan siap untuk menyaingi usahanya. Oleh karenanya pelaku usaha kecil perlu diberikan pemahaman tentang pentingnya daya saing produk yang salah satunya usaha Lillah Hijab.

Lillah Hijab merupakan salah satu home industry yang bergerak dibidang produksi hijab atau kerudung. Lillah Hijab berdiri sejak Januari 2018 dan berlokasi di Jalan Tuah Karya Putri Harapan Kos Bunda, Panam Kel. Tuah Karya Kec. Tampan. Usaha rumahan ini sendiri lebih mengutamakan kualitas produk karna dengan kualitas yang baik maka konsumen pun akan merasa puas dengan produk tersebut. Jenis produk yang dihasilkan dari Lillah Hijab adalah bella square.

Banyaknya usaha sejenis bergerak dibidang yang sama yaitu usaha rumahan dan shop online. Adapun pesaing usaha yaitu seperti Yr Hijab dan Hayrin Hijab. Usaha Yr Hijab berdiri sejak Juli 2018, sedangkan usaha Hayrin Hijab berdiri sejak November 2018. Bertambahnya perusahaanperusahaan pesaing yang sama menunjukan tingkat persaingan dalam memperoleh pangsa pasar semakin ketat, membuat manajemen perusahaan harus bekerja keras mencari cara dan strategi untuk menemukan peluang terkecil sekalipun untuk mendapatkan pasar yang ada sekarang. Pengolahan data menggunakan teknik analisis yang tradisional tidak dapat digunakan untuk mengekstrak informasi yang ada pada databased dalam jumlah yang besar [1]. Untuk mendapatkan informasi yang membantu perusahaan dalam meningkatkan proses bisnis dilakukan perbandingan antar perusahaan menggunakan benchmarking untuk mencipatkan keunggulan bersaing perusahaan itu sendiri.

Permasalahan Lillah Hijab yaitu penjualan selama dua tahun menunjukan terjadinya fluktuasi yang dalam penjualan kerudung. Hal ini dapat dilihat pada gambar 1 dibawah ini.

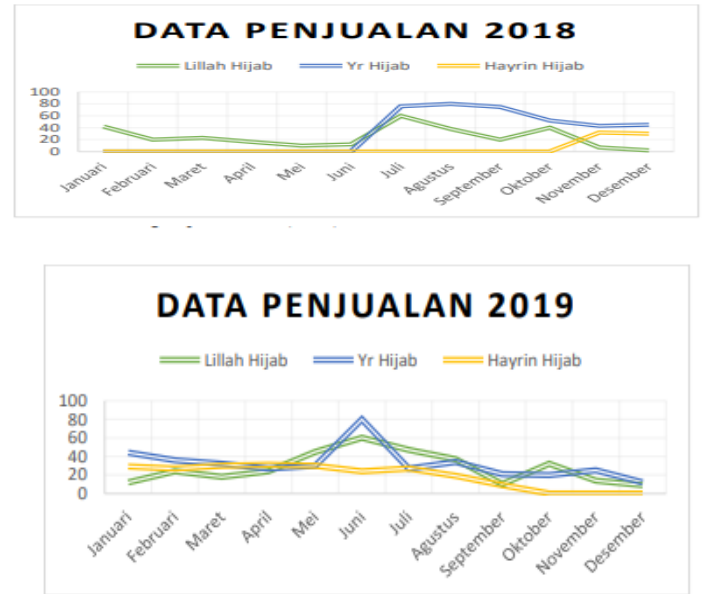

Gambar 1. Data Penjualan 2018-2019

Berdasarkan gambar 1 diatas terjadi karena konsumen yang memesan tidak menentu sehingga penjualan dari bulan kebulan berbeda bahkan semakin banyak yang menurun. Promosi yang dilakukan dengan bantuan media sosial dan melakukan bazar.

Berdasarkan permasalahan diatas perlu dilakukan evaluasi terhadap kelemahan, kekuatan, peluang dan ancaman produk yang diproduksi dari Lillah Hijab menggunakan dua metode yaitu Matriks BCG, dan Analisa SWOT. Metode Boston Consulting Group (BCG) yaitu menyusun perencanaan strategi bisnis dengan melakukan kegiatan pada potensi dari keuntungan perusahaan. [2]. Analisis SWOT yaitu merumuskan strategi perusahaan dengan memaksimalkan kekuatan (Strengh), peluang (Oppurtunities) dan meminimalkan kelemahan (Weaknesses), ancaman (Threats) [3].

Menurut [2] menyebutkan produk adalah segala sesuatu yang ditawarkan kepasar untuk mendapatkan perhatian, dibeli, digunakan, atau dikonsumsi yang mana dapat memuaskan keinginan atau kebutuhan. Secara konsep produk merupakan pemahaman dari subyektif produsen yang ditawarkan sebagai usaha untuk mendapatkan tujuan melalui pemenuhan kebutuhan dan kegiatan konsumen. Produk adalah segala sesuatu yang ditawarkan oleh pasar atau produsen untuk dapat menarik perhatian konsumen sehingga dapat memenuhi kebutuhan konsumen. Produk dipandang penting konsumen dan dijadikan dasar pengambilan keputusan [4].

Menurut Sarjono (2014) benchmarking dalam dunia usaha merupakan proses membandingkan produk, jasa atau praktik suatu organisasi terhadap kompetitor untuk menentukan apa yang harus dilakukan untuk mencapai tingkat kinerja yang tinggi [5]. 
BCG merupakan metode yang digunakan dalam menyusun suatu perencanaan unit bisinis strategi dengan melakukan pengklasifikasian terhadap potensi keuntungan perusahaan, kemudian dimasukan ke matriks Boston Consulting Group, secara grafis menunjukan perbedaan antara berbagai divisi dalam posisi pangsa pasar relatif dan tingkat pertumbuhan pasar.

Menurut Senthilkumar, dkk : (2014) keuntungan menggunakan matriks IFE dan EFE adalah yang pertama tidak memerlukan keterampilan tertentu karena sudah mudah digunakan. Kedua mudah dimengerti sehingga terhindarkan dari kesalahpahaman. Ketiga befokus pada faktor-faktor internal dan eksternal yang mempengaruhi strategi pemasaran. Keempat dapat digunakan untuk membangun yang lain, seperti matriks IE dan analisis SWOT [6].

SWOT adalah singkatan dari lingkungan internal Strenghts dan Weaghtnesses serta lingkungan eksternal Oppurtinities dalam threats yang dihadapi dua bisnis. Analisa SWOT membandingkan antara faktor eksternal peluang dan ancam an dengan faktor internal kekuatan dan kelemahan [3].

\section{Metode Penelitian}

Jenis data yang digunakan dalam penelitian ini adalah data primer dan data sekunder. Data primer data yang diperoleh dari observasi dan pengamatan secara langsung berupa wawancara dan penyebaran kusioner. Adapun data sekunder ini adalah data yang secara tidak langsung diamati oleh peneliti. Data tersebut berupa file profil perusahaan.

\section{Hasil dan Pembahasan}

Data yang digunakan untuk matriks BCG (Boston Consulting Group) yaitu data volume penjualan Lillah Hijab dan total volume penjualan pesaing, selanjutnya untuk menentukan kuadran matriks BCG pada perusahaan dengan menghitung tingkat pertumbuhan pasar dan pangsa pasar relatif perusahaan.

1. Perhitungan Tingkat Pertumbuhan Pasar (Market Grow Rate)

$$
\begin{aligned}
\mathrm{TPP} & =\frac{\mathrm{VPN}-\mathrm{VP}-1}{\mathrm{VPN}-1} \times 100 \% \\
& =\frac{\mathrm{VP} 2019-\mathrm{VP} 2018}{\mathrm{VP} 2018} \times 100 \% \\
& =\frac{\mathrm{VP} 2019-\mathrm{VP} 2018}{\mathrm{VP} 2018} \times 100 \% \\
& =\frac{8.280 .000-7.250 .000}{7.250 .000} \times 100 \% \\
& =14,2 \%
\end{aligned}
$$

Berdasarkan hasil perhitugan tingkat pertumbuhan pasar didapatkan hasil yaitu 14,2\% . Hal ini menunjukkan tingkat pertumbuhan pasar yang tinggi, yang dilihat dari kenaikan penjualan dari tahun 2018 ke 2019. Walaupun pada bulanbulan tertentu mengalami penurunan penjualan.

2. Pangsa Pasar Relatif (Relative Market Share)

Pangsa pasar relatif adalah proporsi kemampuan perusahaan pada penjualan keseluruhan pesaing dan pada perusahaan itu sendiri. Pangsa pasar relatif dapat dihitung dengan cara:

$$
\begin{aligned}
\text { PPR } & =\frac{V P N}{V P P ~ N} \\
\text { PPR } & =\frac{8.280 .000}{9.700 .000} \\
& =0,85<1
\end{aligned}
$$

Hasil perhitungan pada tingkat pangsa pasar relatif Lillah Hijab dibandingkan dengan perusahaan pesaing yaitu sebesar 0,85 .

Analisis yang dilakukan menggunakan matriks BCG dengan membandingkan tingkat pertumbuhan pasar dan pangsa pasar relatif, maka posisi Lillah Hijab pada matrik BCG dapat dilihat pada Gambar 1:

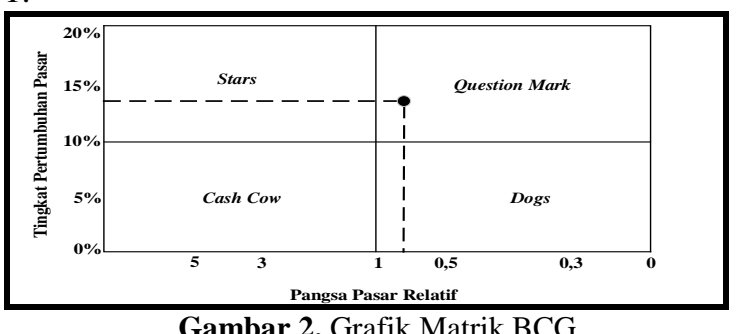

Gambar 2. Grafik Matrik BCG

Berdasarkan Gambar 1 hasil perhitungan pada matriks BCG dapat dilihat bahwa Lillah Hijab dengan pesaing berada pada posisi Question Mark, dengan perhitungan pasar $14,2 \%$ dan perhitungan pangsa pasar relatif 0,85 yang mana posisi perusahaan berada dalam kondisi pangsa pasar yang rendah dan terjadi kondisi pertumbuhan yang tinggi, sehingga bahwa cash flow lemah. Perusahaan ini memerlukan peningkatan dan pengembangan produk baru yang nantinya akan di produksi agar bisa mengikuti kondisi keinginan pasar yang tinggi.

\section{Matriks IFE (Internal Factor Evaluation)}

Analisis matriks IFE adalah hasil dari identifikasi faktor internal berupa kekuatan (Strength) dan kelemahan (Weakness) yang mempengaruhi Lillah Hijab. Penentuan rating dan bobot Matriks IFE diperoleh dari 2 (dua) orang responden yang terdiri dari pemilik usaha dan 1 (satu) karyawan yang bekerja di Lillah Hijab. Sedangkan hasil dari total skor didapatkan dari 
mengalikan bobot dan rating. Berikut Tabel 1 Hasil Bobot Analisa Matriks IFE Lillah Hijab:

Tabel 1. Hasil Bobot Analisa Matriks IFE Lillah Hijab

\begin{tabular}{|c|c|c|c|c|}
\hline \multirow[t]{2}{*}{ No } & \multirow{2}{*}{$\begin{array}{c}\text { Faktor Internal } \\
\text { Kekuatan (Strength) }\end{array}$} & \multicolumn{2}{|c|}{ Bobot } & \multirow{2}{*}{$\begin{array}{c}\text { Rata- } \\
\text { rata }\end{array}$} \\
\hline & & 1 & 2 & \\
\hline 1 & $\begin{array}{l}\text { Modal sendiri dari } \\
\text { perusahaan }\end{array}$ & 0,07 & 0,09 & 0,08 \\
\hline 2 & $\begin{array}{l}\text { Menggunakan } \\
\text { media sosial }\end{array}$ & 0,1 & 0,09 & 0,095 \\
\hline 3 & $\begin{array}{c}\text { Harga masih } \\
\text { terjangkau }\end{array}$ & 0,07 & 0,06 & 0,065 \\
\hline 4 & $\begin{array}{l}\text { Melakukan promosi } \\
\text { dimedia social } \\
\text { secara aktif }\end{array}$ & 0,16 & 0,15 & 0,155 \\
\hline \multirow[t]{2}{*}{5} & $\begin{array}{c}\text { Pemilik mengatur } \\
\text { dan mengontrol } \\
\text { produksi secara } \\
\text { rutin }\end{array}$ & 0,07 & 0,08 & 0,075 \\
\hline & Faktor Eksternal & \multicolumn{2}{|c|}{ Bobot } & Rata- \\
\hline No & Kekuatan (Strength) & 1 & 2 & rata \\
\hline 1 & $\begin{array}{l}\text { Model produksi } \\
\text { hamper sama } \\
\text { dengan produk } \\
\text { pesaing }\end{array}$ & 0,08 & 0,1 & 0,09 \\
\hline 2 & $\begin{array}{c}\text { Produk yang } \\
\text { dihasilkan hanya } \\
\text { satu jenis } \\
\end{array}$ & 0,11 & 0,12 & 0,115 \\
\hline 3 & Masih minim modal & 0,1 & 0,1 & 0,1 \\
\hline 4 & $\begin{array}{l}\text { Belum mempunyai } \\
\text { toko sendiri }\end{array}$ & 0,11 & 0,1 & 0,15 \\
\hline 5 & $\begin{array}{l}\text { Jumlah karyawan } \\
\text { hanya satu orang }\end{array}$ & 0,08 & 0,07 & 0,075 \\
\hline mla & & & & 1,00 \\
\hline
\end{tabular}

Berdasarkan dari Tabel 1 Hasil Bobot Analisa Matriks IFE berupa faktor internal yaitu kekuatan dan kelemahan pada Lillah Hijab. Maka hasil dari jumlah rata-rata nya adalah 1,00 . Bobot tersebut mendapatkan skor yang paling besar yaitu faktor internal kekuatan pada Lillah Hijab adalah melakukan promosi di media sosial secara aktif dengan skor 0,155. Berikut cara melakukan perhitungan nilai dari rata-rata bobot:

Rata-rata bobot faktor internal kekuatan 4

$=\frac{\text { Bobot } 1+\text { Bobot } 2}{2}$

Rata-rata bobot faktor internal kekuatan 4

$=\frac{0,16+0,15}{2}$
$=0,155$

Berikut Tabel 2 Hasil Rating Analisa Matriks IFE Lillah Hijab:

Tabel 2. Hasil Rating Analisa Matriks IFE Lillah Hijab

\begin{tabular}{ccccc}
\hline No & Faktor Internal & \multicolumn{2}{c}{ Rating } & Rata- \\
\cline { 2 - 4 } & Kekuatan (Strength) & 1 & 2 & rata \\
\hline 1 & Modal sendiri dari & 4 & 3 & 3,5 \\
\hline
\end{tabular}

\begin{tabular}{|c|c|c|c|c|}
\hline & perusahaan & & & \\
\hline 2 & $\begin{array}{l}\text { Menggunakan media } \\
\text { sosial }\end{array}$ & 4 & 3 & 3,5 \\
\hline 3 & $\begin{array}{c}\text { Harga masih } \\
\text { terjangkau }\end{array}$ & 3 & 3 & 3 \\
\hline 4 & $\begin{array}{c}\text { Melakukan promosi } \\
\text { dimedia social secara } \\
\text { aktif }\end{array}$ & 4 & 4 & 4 \\
\hline 5 & $\begin{array}{l}\text { Pemilik mengatur } \\
\text { dan mengontrol } \\
\text { produksi secara rutin }\end{array}$ & 3 & 4 & 3,5 \\
\hline & Faktor Eksternal & \multicolumn{2}{|c|}{ Bobot } & Rata- \\
\hline No & Kekuatan (Strength) & 1 & 2 & rata \\
\hline 1 & $\begin{array}{l}\text { Model produksi } \\
\text { hamper sama dengan } \\
\text { produk pesaing }\end{array}$ & 2 & 1 & 1,5 \\
\hline 2 & $\begin{array}{c}\text { Produk yang } \\
\text { dihasilkan hanya satu } \\
\text { jenis }\end{array}$ & 2 & 2 & 2 \\
\hline 3 & Masih minim modal & 1 & 1 & 1 \\
\hline 4 & $\begin{array}{l}\text { Belum mempunyai } \\
\text { toko sendiri }\end{array}$ & 1 & 1 & 1 \\
\hline 5 & $\begin{array}{l}\text { Jumlah karyawan } \\
\text { hanya satu orang }\end{array}$ & 2 & 2 & 2 \\
\hline Jumlah & & & & 25 \\
\hline
\end{tabular}

Berdasarkan dari Tabel 2 bahwa hasil dari rating analisa matriks IFE Lillah Hijab mendapatkan jumlah rata-rata 25 dari faktor internal yaitu kekuatan (strength) dan kelemahan (weakness). Rating tersebut mendapatkan skor yang paling besar adalah melakukan promosi di media sosial secara aktif dengan skor 4. Berikut cara melakukan perhitungan nilai dari rata-rata bobot: Rata-rata bobot faktor internal kelemahan 3 $=\frac{\text { Rating } 1+\text { Rating } 2}{2}$

Rata-rata bobot faktor internal kelemehan 3

$=\frac{4+4}{2}$

$=4$

Berikut Tabel 3 hasil rekapitulasi matriks IFE Lillah Hijab:

Tabel 3. Hasil Rekapitulasi Matriks IFE Lillah Hijab

\begin{tabular}{ccccc}
\hline No & \begin{tabular}{c} 
Faktor Internal \\
\cline { 2 - 3 }
\end{tabular} $\begin{array}{c}\text { Kekuatan } \\
\text { (Strength) }\end{array}$ & Bobot & Rating & $\begin{array}{c}\text { Rata- } \\
\text { rata }\end{array}$ \\
\hline 1 & $\begin{array}{c}\text { Modal sendiri } \\
\text { dari perusahaan }\end{array}$ & 0,08 & 3,5 & 0,28 \\
\hline 2 & $\begin{array}{c}\text { Menggunakan } \\
\text { media sosial }\end{array}$ & 0,095 & 3,5 & 0,3325 \\
\hline 3 & $\begin{array}{c}\text { Harga masih } \\
\text { terjangkau }\end{array}$ & 0,065 & 3 & 0,195 \\
\hline 5 & $\begin{array}{c}\text { Melakukan } \\
\text { promosi } \\
\text { dimedia social } \\
\text { secara aktif }\end{array}$ & 0,155 & 4 & 0,62 \\
\hline 5 & $\begin{array}{c}\text { Pemilik } \\
\text { mengatur dan }\end{array}$ & 0,075 & 3,5 & 0,2625 \\
\hline
\end{tabular}




\begin{tabular}{|c|c|c|c|c|}
\hline & $\begin{array}{c}\text { mengontrol } \\
\text { produksi secara } \\
\text { rutin }\end{array}$ & & & \\
\hline \multirow[b]{2}{*}{ No } & $\begin{array}{c}\text { Faktor } \\
\text { Eksternal }\end{array}$ & \multirow{2}{*}{ Bobot } & \multirow{2}{*}{ Rating } & \multirow{2}{*}{$\begin{array}{l}\text { Rata- } \\
\text { rata }\end{array}$} \\
\hline & $\begin{array}{l}\text { Kekuatan } \\
\text { (Strength) }\end{array}$ & & & \\
\hline 1 & $\begin{array}{c}\text { Model } \\
\text { produksi } \\
\text { hamper sama } \\
\text { dengan produk } \\
\text { pesaing }\end{array}$ & 0,09 & 1,5 & 0,135 \\
\hline 2 & $\begin{array}{c}\text { Produk yang } \\
\text { dihasilkan } \\
\text { hanya satu } \\
\text { jenis }\end{array}$ & 0,075 & 2 & 0,135 \\
\hline 3 & $\begin{array}{l}\text { Masih minim } \\
\text { modal }\end{array}$ & 0,1 & 1 & 0,1 \\
\hline 4 & $\begin{array}{c}\text { Belum } \\
\text { mempunyai } \\
\text { toko sendiri }\end{array}$ & 0,15 & 1 & 0,15 \\
\hline 5 & $\begin{array}{c}\text { Jumlah } \\
\text { karyawan } \\
\text { hanya satu } \\
\text { orang }\end{array}$ & 0,115 & 2 & 0,23 \\
\hline Jumlah & & 1,00 & 25 & 2,455 \\
\hline
\end{tabular}

Berdasarkan pada Tabel 3 dapat dilihat bahwa hasil perhitungan dengan menggunakan matriks IFE didapatkan total skor Lillah Hijab sebesar 2,455. Skor pada posisi internal Lillah Hijab masih belum mampu mengatasi kelemahan dan belum merespon dengan baik faktor internal pada perusahaan itu sendiri. Hasil pada Tabel 3 menunjukkan bahwa kekuatan utama Lillah Hijab adalah melakukan promosi di media sosial secara aktif dengan skor 0,62. Sedangkan kelemahan utama Lillah Hijab adalah masih minimnya modal dengan skor 0,1 .

\section{Matriks EFE (External Factor Evaluation)}

Analisis matrik EFE adalah hasil identifikasi faktor eksternal berupa peluang (Oppurtunitties) dan ancaman (Threaths) yang berpengaruh terhadap Lillah Hijab. Penentuan rating dan bobot Matriks EFE diperoleh dari 2 (dua) orang responden yang terdiri dari pemilik usaha dan 1 karyawan yang bekerja di Lillah Hijab. Sedangkan hasil dari total skor didapatkan dari mengalikan bobot dan rating. Berikut Tabel 4 Hasil Bobot Analisa Matriks EFE Lillah Hijab:

Tabel 4. Hasil Bobot Analisa Matriks IFE Lillah Hijab

\begin{tabular}{ccccc}
\hline No & Faktor Eksternal & \multicolumn{2}{c}{ Bobot } & Rata- \\
\cline { 2 - 4 } & $\begin{array}{c}\text { Peluang } \\
\text { (Opportunitties) }\end{array}$ & 1 & 2 & rata \\
\hline 1 & $\begin{array}{c}\text { Gaya hidup yang } \\
\text { selalu berganti } \\
\text { dan tidak pernah } \\
\text { puas }\end{array}$ & 0,08 & 0,09 & 0,085 \\
\hline 2 & $\begin{array}{c}\text { Perkembangan } \\
\text { dunia promosi }\end{array}$ & 0,13 & 0,13 & 0,13 \\
\hline
\end{tabular}

\begin{tabular}{|c|c|c|c|c|}
\hline & $\begin{array}{l}\text { sudah maju } \\
\text { menggunakan } \\
\text { internet }\end{array}$ & & & \\
\hline 3 & $\begin{array}{c}\text { Penyediaan } \\
\text { bahan baku yang } \\
\text { mudah didapat }\end{array}$ & 0,08 & 0,07 & 0,075 \\
\hline 4 & $\begin{array}{c}\text { Semakin tahun } \\
\text { ketahun } \\
\text { bertambahnya } \\
\text { populasi } \\
\text { penduduk } \\
\text { mayoritas } \\
\text { muslimah (islam) }\end{array}$ & 0,1 & 0,12 & 0,11 \\
\hline \multirow[t]{2}{*}{ No } & $\begin{array}{c}\text { Faktor } \\
\text { Eksternal }\end{array}$ & \multicolumn{2}{|c|}{ Bobot } & $\begin{array}{c}\text { Rata- } \\
\text { rata }\end{array}$ \\
\hline & $\begin{array}{l}\text { Ancaman } \\
\text { (Threaths) }\end{array}$ & 1 & 2 & \\
\hline 1 & $\begin{array}{c}\text { Naiknya harga } \\
\text { bahan baku }\end{array}$ & 0,1 & 0,2 & 0,15 \\
\hline 2 & $\begin{array}{l}\text { Pelanggan } \\
\text { beralih dengan } \\
\text { pesaing yang } \\
\text { sejenis }\end{array}$ & 0,12 & 0,1 & 0,11 \\
\hline 3 & $\begin{array}{c}\text { Produk dari } \\
\text { perusahaan lain } \\
\text { menghasilkan } \\
\text { produk yang } \\
\text { lebih kreatif dan } \\
\text { inovatif }\end{array}$ & 0,1 & 0,1 & 0,1 \\
\hline 4 & $\begin{array}{l}\text { Bertambahnya } \\
\text { pesaing baru } \\
\text { yang tidak } \\
\text { sejenis }\end{array}$ & 0,07 & 0,09 & 0,08 \\
\hline 5 & $\begin{array}{l}\text { Banyaknya } \\
\text { produk lain } \\
\text { dilakukan } \\
\text { dengan subtitusi }\end{array}$ & 0,15 & 0,13 & 0,14 \\
\hline 6 & $\begin{array}{l}\text { Ketidak tetapan } \\
\text { pada nilai tukar } \\
\text { uang }\end{array}$ & 0,02 & 0,02 & 0,02 \\
\hline Jumlah & & & & 1,00 \\
\hline
\end{tabular}

Berdasarkan dari Tabel 4 Hasil Bobot Analisa Matriks EFE berupa faktor eksternal yaitu peluang dan ancaman pada Lillah Hijab. Maka hasil dari jumlah rata-rata nya adalah 1,00 . Bobot tersebut mendapatkan skor yang paling besar yaitu faktor eksternal peluang pada Lillah Hijab adalah perkembangan dunia promosi sudah maju menggunakan internet. Berikut cara melakukan perhitungan nilai dari rata-rata bobot:

Rata-rata bobot faktor eksternal peluang 2 $=\frac{\text { Bobot } 1+\text { Bobot } 2}{2}$

Rata-rata bobot faktor ekstenal peluang 2 $=\frac{0,13+0,13}{2}$

$=0,13^{2}$

Perhitungan ini dilakukan secara bertahap dari faktor eksternal peluang (oppurtunitties) sampai faktor eksternal ancman (threaths). Selanjutnya melakukan perhtiungan nilai rating matriks IFE. 
Berikut Tabel 5 Hasil Rating Analisa Matriks EFE Lillah Hijab:

Tabel 5. Hasil Rating Analisa Matriks EFE Lillah Hijab

\begin{tabular}{|c|c|c|c|c|}
\hline \multirow[b]{2}{*}{ No } & \multirow{2}{*}{$\begin{array}{c}\text { Faktor Eksternal } \\
\text { Peluang } \\
\text { (Opportunitties) }\end{array}$} & \multicolumn{2}{|c|}{ Rating } & \multirow[b]{2}{*}{$\begin{array}{c}\text { Rata- } \\
\text { rata }\end{array}$} \\
\hline & & 1 & 2 & \\
\hline 1 & $\begin{array}{c}\text { Gaya hidup yang } \\
\text { selalu berganti } \\
\text { dan tidak pernah } \\
\text { puas }\end{array}$ & 4 & 4 & 4 \\
\hline 2 & $\begin{array}{l}\text { Perkembangan } \\
\text { dunia promosi } \\
\text { sudah maju } \\
\text { menggunakan } \\
\text { internet }\end{array}$ & 4 & 4 & 4 \\
\hline 3 & $\begin{array}{c}\text { Penyediaan } \\
\text { bahan baku yang } \\
\text { mudah didapat }\end{array}$ & 3 & 4 & 3,5 \\
\hline
\end{tabular}

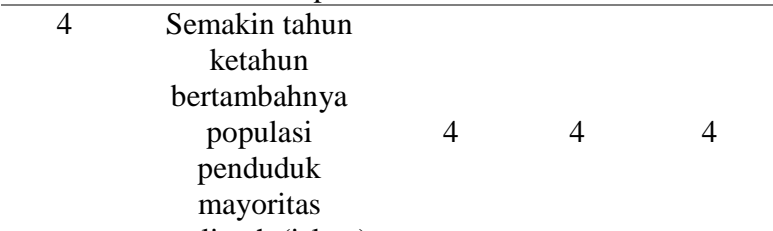

\begin{tabular}{|c|c|c|c|c|}
\hline \multirow[t]{2}{*}{ No } & \multirow{2}{*}{$\begin{array}{c}\text { Faktor } \\
\text { Eksternal } \\
\text { Ancaman } \\
\text { (Threaths) }\end{array}$} & \multicolumn{2}{|c|}{ Rating } & \multirow{2}{*}{$\begin{array}{l}\text { Rata- } \\
\text { rata }\end{array}$} \\
\hline & & 1 & 2 & \\
\hline 1 & $\begin{array}{c}\text { Naiknya harga } \\
\text { bahan baku }\end{array}$ & 3 & 3 & 3 \\
\hline 2 & $\begin{array}{l}\text { Pelanggan } \\
\text { beralih dengan } \\
\text { pesaing yang } \\
\text { sejenis }\end{array}$ & 3 & 2 & 2,5 \\
\hline 3 & $\begin{array}{c}\text { Produk dari } \\
\text { perusahaan lain } \\
\text { menghasilkan } \\
\text { produk yang } \\
\text { lebih kreatif dan } \\
\text { inovatif }\end{array}$ & 2 & 3 & 2,5 \\
\hline 4 & $\begin{array}{c}\text { Bertambahnya } \\
\text { pesaing baru } \\
\text { yang tidak } \\
\text { sejenis }\end{array}$ & 2 & 3 & 2,5 \\
\hline 5 & $\begin{array}{c}\text { Banyaknya } \\
\text { produk lain } \\
\text { dilakukan } \\
\text { dengan subtitusi }\end{array}$ & 1 & 2 & 1,5 \\
\hline 6 & $\begin{array}{c}\text { Ketidak tetapan } \\
\text { pada nilai tukar } \\
\text { uang }\end{array}$ & 3 & 3 & 3 \\
\hline umla & & & & 30,5 \\
\hline
\end{tabular}

Berdasarkan dari Tabel 5 bahwa hasil dari rating analisa matriks EFE Lillah Hijab mendapatkan jumlah rata-rata 30,5 dari faktor internal yaitu kekuatan (strength) dan kelemahan (weakness). Rating tersebut mendapatkan skor yang paling besar pada peluang yaitu perkembangan dunia promosi sudah maju menggunakan internet secara online dengan skor 4. Berikut cara melakukan perhitungan nilai dari rata-rata bobot:

Rata-rata bobot faktor eksternal peluang 2 $=\frac{\text { Bobot } 1+\text { Bobot } 2}{2}$

Rata-rata bobot faktor eksternal peluang 2 $=\frac{4+4}{2}$

$=4$

Perhitungan ini dilakukan secara bertahap dari faktor eksternal yaitu peluang dan ancaman. Selanjutnya untuk mendapatkan nilai skor analisa matiks EFE nilai bobot dikalikan dengan rating. Berikut Tabel 6 hasil rekapitulasi matriks EFE Lillah Hijab:

Tabel 6. Hasil Rekapitulasi Matriks EFE Lillah Hijab

\begin{tabular}{|c|c|c|c|c|}
\hline No & $\begin{array}{c}\text { Faktor Eksternal } \\
\text { Peluang } \\
\text { (Opportunitties) }\end{array}$ & Bobot & Rating & $\begin{array}{l}\text { Rata- } \\
\text { rata }\end{array}$ \\
\hline 1 & $\begin{array}{c}\text { Gaya hidup yang } \\
\text { selalu berganti } \\
\text { dan tidak pernah } \\
\text { puas }\end{array}$ & 0,085 & 4 & 0,34 \\
\hline 2 & $\begin{array}{l}\text { Perkembangan } \\
\text { dunia promosi } \\
\text { sudah maju } \\
\text { menggunakan } \\
\text { internet }\end{array}$ & 0,13 & 4 & 0,52 \\
\hline 3 & $\begin{array}{c}\text { Penyediaan } \\
\text { bahan baku yang } \\
\text { mudah didapat }\end{array}$ & 0,075 & 3,5 & 0,2625 \\
\hline 4 & $\begin{array}{c}\text { Semakin tahun } \\
\text { ketahun } \\
\text { bertambahnya } \\
\text { populasi } \\
\text { penduduk } \\
\text { mayoritas } \\
\text { muslimah (islam) }\end{array}$ & 0,11 & 4 & 0,44 \\
\hline No & $\begin{array}{c}\text { Faktor Eksternal } \\
\text { Ancaman } \\
\text { (Threaths) }\end{array}$ & Bobot & Rating & $\begin{array}{l}\text { Rata- } \\
\text { rata }\end{array}$ \\
\hline 1 & $\begin{array}{c}\text { Naiknya harga } \\
\text { bahan baku }\end{array}$ & 0,15 & 3 & 0,45 \\
\hline 2 & $\begin{array}{c}\text { Pelanggan beralih } \\
\text { dengan pesaing } \\
\text { yang sejenis }\end{array}$ & 0,11 & 2,5 & 0,275 \\
\hline 3 & $\begin{array}{l}\text { Produk dari } \\
\text { perusahaan lain } \\
\text { menghasilkan } \\
\text { produk yang } \\
\text { lebih kreatif dan } \\
\text { inovatif }\end{array}$ & 0,1 & 2,5 & 0,25 \\
\hline 4 & $\begin{array}{c}\text { Bertambahnya } \\
\text { pesaing baru } \\
\text { yang tidak sejenis }\end{array}$ & 0,08 & 2,5 & 0,2 \\
\hline 5 & $\begin{array}{c}\text { Banyaknya } \\
\text { produk lain } \\
\text { dilakukan dengan } \\
\text { subtitusi }\end{array}$ & 0,14 & 1,5 & 0,21 \\
\hline 6 & $\begin{array}{l}\text { Ketidak tetapan } \\
\text { pada nilai tukar }\end{array}$ & 0,2 & 3 & 0,6 \\
\hline
\end{tabular}




\begin{tabular}{l}
\hline uang \\
\hline Jumlah 1,00 \\
Berdasarkan pada Tabel 6 dapat dilihat bahwa hasil \\
perhitungan dengan menggunakan matriks EFE \\
didapatkan total skor Lillah Hijab sebesar 3,5475. Skor \\
pada posisi eksternal Lillah Hijab sudah mampu \\
merespon dengan baik dalam memanfaatkan peluang \\
untuk mengatasi ancaman. Hasil pada Tabel 5 \\
menunjukkan bahwa peluang utama Lillah Hijab adalah \\
perkembangan dunia promosi sudah maju menggunakan \\
internet dengan skor 0,52. Sedangkan ancaman utama \\
Lillah Hijab adalah naiknya harga bahan baku dengan \\
skor 0,45.
\end{tabular}

\section{Matriks IE (Internal Eksternal)}

Berdasarkan hasil yang diperoleh pada matrik IFE dan EFE maka tahap selanjutnya yaitu menyusun matrik IE atau matrik (internal-eksternal). Matrik IE dilakukan untuk mengetahui dan menganalisis posisi pada perusahaan secara detail dan juga untuk melihat strategi yang tepat diterapkan pada Lillah Hijab. Matrik IE melakukan penilaian dari nilai skor IFE dan EFE yaitu sebesar 2,455 dan 3,5475 yang menunjukkan posisi Lillah Hijab terletak pada kuadran II. Pada posisi kuadran II strategi yang digunakan yaitu strategi tumbuh dan membangun. Strategi ini meningkatkan pada penjualan pasar, pengembangan pada pasar, dan pada pengembangan produk yang diterapkan untuk Lillah Hijab. Maka grafik matrik IE dapat dilihat pada Gambar 2:

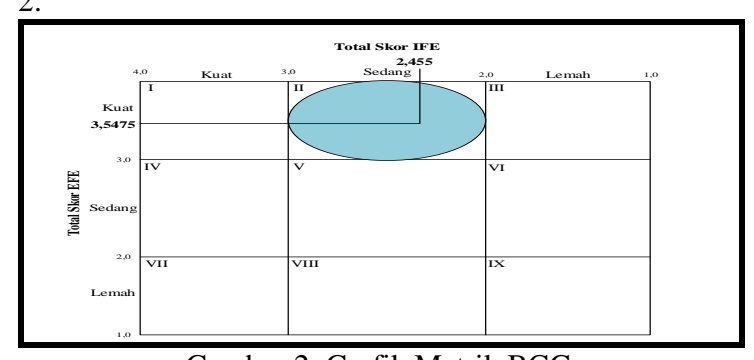

Gambar 2. Grafik Matrik BCG

\section{Analisis Matrik SWOT}

Berdasarkan penyusunan strategi pada analisis matrik SWOT yang didapat dari kekuatan (Strengths), kelemahan (Weakness), peluang (Oppurtunitties), dan ancaman (Threats) menghasilkan beberapa strategi alternatif yang diperoleh dari empat sel, antara lain sebagai berikut:

Tabel 7 Hasil Analisis Matrik SWOT pada Lillah Hijab

\begin{tabular}{l} 
Faktor Internal \\
\cline { 2 - 6 }
\end{tabular}

$\begin{array}{lll}\text { Ancaman }(\mathrm{T}) & \text { Strategi ST } & \text { Strategi WT }\end{array}$


1. Naiknya harga bahan baku

2. Pelanggan beralih dengan pesaing yang sejenis

3. Produk dari perusahaan lain menghasilkan produk yang lebih kreatif dan inovatif

4. Betambahnya pesaing baru yang tidak sejenis

5. Banyaknya produk lain dilakukan dengan subtitusi

6. Ketidak tetapan nilai tukar uang
1. Menetapkan harga sesuai dengan perubahan harga bahan baku, tetap memperhatikan kebutuhan pelanggan tanpa merugikan perusahaan

2. Menambah beberapa jenis produk yang baru dengan memperhatikan kualitas agar dapat bersaing dengan produk yang tidak sejenis maupun yang sejenis

\section{Kesimpulan}

Berdasarkan hasil dari penelitian yang dilakukan, maka dapat di simpulkan bahwa:

1. Penggunaan matriks BCG dengan menghitung tingkat pertumbuhan pasar bahwa Lillah Hijab terletak pada posisi Question Mark sebesar 14,2 $\%$ dan pada perhitungan pangsa pasar relatif bahwa posisi Lillah hijab menghadapi pangsa pasar yang rendah dan terjadi kondisi pertumbuhan yang tinggi dengan nilai sebesar 0,85 . Perusahaan ini memerlukan peningkatan dan pengembangan produk baru yang nantinya akan di produksi agar bisa mengikuti kondisi keinginan pasar yang tinggi. Melakukan pengembangan produk dan peningkatan jenis produk yang baru, dari segi bahan baku, model hijab yang baru, menambah berbagai ukuran agar konsumen lebih puas dalam memilih produk.

2. Hasil dari analisis SWOT terdapat beberapa bagian yaitu Faktor Internal, Faktor Eksternal, Matrik IE, dan strategi pemasasran yang efektif dalam meningkatkan penjualan Lillah Hijab sebagai berikut:

a. Faktor Internal Faktor internal dilakukan agar mengetahui kekuatan dan kelemahan pada perusahaan. Bardasarkan hasil analisis faktor internal perusahaan maka dapat disimpulkan bahwa kekuatan perusahaan adalah pemilik mengatur dan mengontrol produksi secara rutin. Harga yang masih terjangkau, melakukan promosi dimedia sosial secara aktif. Modal sendiri dari perusahaan Lillah Hijab. Dan menggunakan media sosial untuk melakukan informasi.

b. Faktor Eksternal dilakukan untuk mengetahui faktor peluang pada perusahaan dan ancaman yang perlu dihindari. Peluang pada perusahaan adalah penyediaan bahan baku yang mudah didapat, gaya hidup yang selalu berganti dan tidak pernah puas, perkembangan dunia promosi sudah maju menggunakan internet. Semakin tahun ketahun
1. Mengumpulkan informasi dalam pengembangan dan pemasaran produk

2. Melakukan kerjasama yang baik dengan penyedia bahan baku dan investor agar dapat meningkatkan kapasistas produksi bertambahnya populasi penduduk mayoritas muslimah (islam). Ancaman yang perlu dihindari yaitu naiknya harga bahan baku, ketidak tetapan pada nilai tukar uang, pelanggan beralih dengan pesaing yang sejenis, bertambahnya pesaing baru yang tidak sejenis, produk dari perusahaan lain menghasilkan produk yang lebih kreatif dan inovatif, banyaknya produk lain dilakukan dengan subtitusi.

c. Matriks Internal-Eksternal Matriks IE atau matriks Internal-Eksternal didapat dari hasil Matriks IFE dan EFE dilakukan untuk mengetahui dan menganalisis posisi pada perusahaan secara detail dan juga untuk melihat strategi yang tepat diterapkan pada Lillah Hijab. Berdasarkan hasil skor yang telah di olah matrik IFE sebesar 2,455 dan matrik EFE sebesar 3,5475, maka matrik IE mendapatkan nilai raata-rata yang menunjukkan posisi Lillah Hijab terletak pada kuadran II. Posisi ini digunakan untuk strategi tumbuh dan membangun.

3. Strategi Perusahaan yang Efektif dalam Meningkatkan Penjualan Lillah Hijab Strategi SO (Strengths-Opportunitties) melakukan kerjasama yang baik kepada karyawan dan distributor, melakukan potongan harga disetiap hari spesial, mempertahankan dan meningkatkan kualitas pada produk. Strategi ST (StrengthsOpportunitties) menetapkan harga sesuai dengan perubahan harga bahan baku, tetap memperhatikan kebutuhan pelanggan tanpa merugikan perusahaan, dan menambah beberapa jenis produk yang baru dengan memperhatikan kualitas agar dapat bersaing dengan produk yang tidak sejenis maupun yang sejenis. Strategi W-O (Weaknesses-Opportunities) menambah modal dengan melakukan kerjasama investor atau melakukan peminjaman kepada bank, melakukan kerjasama dengan agen-agen gunanya untuk memperluas area pemasaran, membuka toko sendiri di perkotaan, serta memperluas pangsa pasar dengan mengikuti strategi penjualan online, yang dan melakukan pengembangan produk agar 
menarik pelanggan. Strategi W-T (WeaknessesThreaths) mengumpulkan informasi dalam pengembangan dan pemasaran produk dan melakukan kerjasama yang baik dengan penyedia bahan baku dan investor agar dapat meningkatkan kapasitas produksi.

\section{Daftar Pustaka}

[1] Rizki, M., Devrika, D., \& Umam, I. H. (2020). Aplikasi Data Mining dalam Penentuan Layout Swalayan dengan Menggunakan Metode MBA. Jurnal Teknik Industri: Jurnal Hasil Penelitian dan Karya Ilmiah dalam Bidang Teknik Industri, 5(2), 130-138.

[2]Kotler., Philip., Prinsip-prinsip Pemasaran (Principles of Marketing). 2008.

[3]Rangkuti., Freddy., Analisis SWOT: Teknik Membedah Kasus Bisnis. PT. Gramedia Pustaka Utama: Jakarta. 1997.

[4]Marendra, I. Gede., (2018). Pengaruh Bauran Pemasaran (Produk, Harga, Lokasi, dan Promosi) Terhadap Keputusan Pembelian Konsumen di Minimarket (Alfamart atau Indomaret). (Studi kasus : Universitas
Pamulang). Jurnal Pemasaran Kompetitif Vol 01 No 03.

[5]Setiawan., Reagan., (2016). Evaluasi Kontribusi Komitmen Terhadap Kinerja Eksekutif Showcase dengan Metode Benchmarking. Jurnal Manajemen dan Start-Up Bisnis Vol 01 No 04.

[6]Alamanda., Dini Turipanam, et al. (2019)."Designing Strategies using IFE, EFE, IE, and QSPM Analysis Digital Village Case.The Asian Journal of Technology Management Vol 12 No 1. 